\title{
Saberes limitados: educación femenina en la información cinematográfica italiana (1946-1953) ${ }^{2}$
}

\author{
Limited knowledge: women's education in italian \\ newsreels
}

\section{Resumen}

La instauración de la democracia en Italia a partir de 1946 trajo consigo la reconstrucción de la educación basada en los nuevos principios de igualdad y libertad. Sin embargo, los valores y modelos de la escuela seguían siendo los del fascismo, con una educación separada por géneros: ellas se preparaban para la vida doméstica y ellos para el trabajo. Esta diferenciación de roles establecida en todos los niveles educativos tiene su reflejo en los noticiarios cinematográficos producidos entre 1946 y 1953. En ellos se aprecia el limitado tipo de estudios y niveles académicos realizados por las mujeres italianas en estos años.

Palabras clave: Educación, mujer, Italia, noticiarios cinematográficos

\begin{abstract}
The arrival of democracy in Italy beginning in 1946 brought with it the reconstruction of education based on the new principles of equality and liberty. However, the main values and models in schools were still those of fascism, in which education was gender-based: girls were taught to become homemakers and men were prepared for the workplace. This roledifferentiation of roles that permeated all levels of education is reflected in cinema newsreels produced between 1946 and 1953. These reels show the limited educational and academic levels reached by Italian women in those years.
\end{abstract}

Keywords: Education, Women, Italy, Newsreels.

\section{SUMARIO}

-. Introducción. -. Una escuela para todos: ¿y para todas? -. Una escuela para el matrimonio. -. La universidad es cosa de hombres. -. Conclusiones. - Bibliografía.

\section{Introducción}

Para construir la nueva democracia en la Italia de después de la Segunda Guerra Mundial era necesaria una Constitución, pero también crear los cimientos de la igualdad y la libertad, a través de la educación. Se pretendía conseguir una escuela democrática, a la que tuviera acceso toda la población, una escuela que renovara moralmente al pueblo italiano. Sin embargo, la situación en la que se encontraba

1 Contratada Doctora. Departamento de Historia de la Comunicación Social de la Facultad de Ciencias de la Información de la Universidad Complutense de Madrid; carlotacoronado@ccinf.ucm.es

2 Este artículo es resultado es del Proyecto de Investigación «Diccionario de símbolos políticos y sociales: claves iconográficas, lugares de memoria e hitos simbólicos en el imaginario español del siglo XX» (Ref. HAR2016-77416-P)». 
el país después de la guerra ralentizaría estos cambios. La destrucción material de infraestructuras escolares, la falta de organización y de material didáctico, impedían llevar a cabo la actividad educativa con normalidad. A finales de los años cuarenta, las escuelas estuvieron en pleno funcionamiento, aunque con deficiencias.

Este proceso de reconstrucción de la escuela tiene reflejo en los noticiarios cinematográficos de la posguerra, cuya amplia difusión entre el público les confería una gran influencia social. Hasta la llegada de la televisión, el programa cinematográfico de la mayor parte de las salas de Italia incluía un noticiario antes del largometraje. Tres fueron las productoras que se dedicaron a la realización de noticiarios en este periodo: el Istituto Luce, Incom y Astra Cinematografica ${ }^{3}$. Después de la caída del fascismo desapareció el noticiario Luce, instrumento propagandístico fundamental del Régimen, pero el 19 de junio de 1945 nació su sucesor: el noticiario Nuova Luce. Tuvo, sin embargo, problemas de aceptación por parte del público: recordaba demasiado al fascismo. Por ello, desaparecerá de las pantallas en $1947^{4}$. Su relevo lo tomó la Settimana Incom, un noticiario cinematográfico producido por una empresa privada que realizaba actividades cinematográficas durante el fascismo: Incom (Industria Cortometraggi Milano), fundada en 1938 por Sandro Pallavicini. En 1946 creó la serie de noticiarios bisemanales Settimana Incom, que se editaron hasta 1965. Por último, en 1951, nació el noticiario Mondo Libero, de la Compañía Cinematográfica Astra, del que se realizaron cuatrocientos números entre 1951 y 1959.

Estos noticiarios han sido la base de este estudio. Los tres se encuentran en el archivo cinematográfico del Istituto Luce, uno de los fondos documentales más ricos sobre cine de no ficción del mundo. Después de seleccionar las noticias sobre mujer y educación en la Italia de la segunda posguerra (1946-1953), se ha procedido al análisis desde el punto de vista tanto de la forma como del contenido, de un corpus documental compuesto por treinta y una noticias.

Entre éstas, se encuentran numerosas informaciones sobre los esfuerzos de gobierno y población para abrir las escuelas; también sobre el interés del gobierno por ayudar a los sectores de la población más desfavorecidos, y en especial, a los niños huérfanos. El mayor número de noticias sobre educación, en el período comprendido entre 1946 y el 1953, corresponde a este tipo de información. En un número menor se presenta a la mujer en niveles educativos superiores o en el ámbito universitario. Dentro del total de noticias sobre educación producidas en este periodo, como se explicará en las próximas páginas, las mujeres apenan tienen protagonismo. Sólo hay cuatro noticias de las treinta y una analizadas en las que se centran en la educación femenina. En el resto, las estudiantes forman parte de noticias, cuyo interés no estriba en el componente femenino, sino en otros acontecimientos como ceremonias de inicio o final de curso, visitas oficiales a escuelas, etc. En definitiva, forman parte de los colectivos que han sufrido los desastres de la guerra.

En todo caso, las ausencias también pueden ser muy reveladoras a la hora de valorar qué modelo educativo femenino, con las consiguientes limitaciones, se tra-

3 Todos los noticiarios producidos por estas tres empresas se encuentran actualmente en el Archivo Fotocinematográfico Luce de Roma, consultable además a través de la página web www.archivioluce.com.

4 Se produjeron sólo 22 números entre 1945 y 1947. 
tó de difundir en la Italia de después de la Segunda Guerra Mundial a través de medios de comunicación de masas como el cine, y especialmente, en los noticiarios cinematográficos.

\section{Una escuela para todos: ¿y para todas?}

«La escuela está abierta a todos» comienza el artículo 34 de la Constitución Republicana. Todos los italianos, sin discriminación alguna, tienen el derecho y la obligación a recibir una instrucción. «La instrucción inferior -continúa el artículo 34- impartida durante al menos ocho años, es obligatoria y gratuita».

De esta manera se abría un proceso de escolarización que permitía disminuir los altos índices de analfabetismo del país, sobre todo entre la población femenina. En los datos sobre el analfabetismo desde principios del siglo XX hasta 1951, se manifiesta una tendencia a la reducción. Disminuye el analfabetismo en ambos sexos, pero la tasa es siempre mayor entre la población femenina (tabla I): históricamente el analfabetismo femenino y el masculino siguen dos escalas paralelas, y las mujeres están siempre un peldaño por debajo respecto a los hombres (Ulivieri, 1992: 179). Según datos de 1951, de cada diez chicos, uno era analfabeto, mientras que de cada cien chicas, quince no sabían ni leer ni escribir. En las zonas rurales y en el sur de Italia estas cifras se disparaban.

Tabla I

Tasas de analfabetismo (1901-1951)

\begin{tabular}{|c|c|c|}
\hline Sexo & $\mathbf{1 9 0 1}$ & $\mathbf{1 9 5 1}$ \\
\hline Masculino & 42,5 & 10,5 \\
\hline Femenino & 54,4 & 15,2 \\
\hline Total & 48,5 & 12,9 \\
\hline
\end{tabular}

Fuente: Istat. Sommario di statistiche storiche dell'Italia, Roma, 1976 (Arangio-Ruiz, 1986).

Los noticiarios de la posguerra dan cuenta de la creación del Consiglio Superiore della Pubblica Istruzione (Consejo Superior de la Instrucción Pública), cuyo objetivo es, según el noticiario Incom número 178 (1948), «la renovación de la escuela llena de hombres, educados para vivir con dignidad y fraternidad». Se hace referencia a la reconstrucción de la escuela en general, pero no a problemas, como la elevada tasa de analfabetismo, sobre todo entre las niñas. No se lleva a cabo una campaña informativa ni propagandística para concienciar a la población de la necesidad de llevar a las niñas al colegio.

Aun así, en la segunda posguerra, aumenta la presencia femenina en la escuela elemental. Hasta la Segunda Guerra Mundial, la tasa escolarización femenina era siempre menor de la masculina. Con la ley Casati (1859) se estableció la obligatoriedad de la instrucción elemental también para las niñas, en un país en el que sólo 
el hecho de saber leer y escribir representaba una amenaza y una tentación a la púdica modestia de la mujer (Perugi, 1978: 193). Esta ley, sin embargo, estaba muy lejos de la realidad: muchas familias impedían a sus hijas ir a la escuela. Las mujeres, desde pequeñas, estaban destinadas al ámbito doméstico: no se consideraba necesario que las niñas estudiaran, porque no les serviría para el futuro en familia.

La miseria era el principal problema: en las familias más pobres, las niñas dejaban la escuela para ponerse a trabajar o ayudar en casa. Se prefería invertir en la educación del hijo -aunque no fuera ni trabajador ni inteligente-, porque invertirlos en la hija se entendía como tirar el dinero, porque terminaría casándose y cuidando a los hijos (Boneschi, 1998: 47).

Existían grandes prejuicios contra la educación femenina: el ambiente socio-familiar desanimaba, incluso impedía a las hijas realizar o continuar con los estudios:

No he seguido estudiando porque nadie me lo ha dicho; (...) lo normal era quedarse en casa para ayudar en las tareas domésticas. También era por la mentalidad: se pensaba que a la mujer no le servía para nada estudiar, bastaba que pensara en buscar marido. Mi hermano, sin embargo, ha estudiado: él era un chico y el título le podía servir para encontrar trabajo (...) Me habría gustado seguir estudiando».(Boneschi, 1998; 47).

Con la difusión de la escolarización, se tendía a «legitimar una socialización primaria de las niñas y de las jóvenes, orientadas hacia el ámbito doméstico» (Ulivieri, 1992: 7). Las niñas conocían ambientes distintos al de la propia casa. La escuela representaba para muchas el primer contacto fuera de los muros domésticos. Además, con la escuela, surgían nuevas aspiraciones más allá de la de ser esposa y madre. La mayor parte, sin embargo, estudiaba hasta los diez años -lo que obligaba la ley-, para ponerse a trabajar o ayudar en casa.

El problema de la escolarización femenina no se trata en los noticiarios de la posguerra, pero resulta significativo el hecho de que, en la mayor parte de las noticias sobre educación, siempre aparecen niñas menores de diez años. No hay ninguna noticia sobre la escuela media y superior en la que aparezcan chicas. De las treinta y una noticias analizadas, sólo en cinco de ellas las estudiantes que aparecen tienen más de doce años. En el resto, tanto sobre instrucción como sobre iniciativas relacionadas con la infancia -colonias, centros de acogida-, la edad de las niñas es de menos de diez años. En este sentido, los noticiarios reflejan la realidad: la aulas de los institutos y universidades tenían un componente masculino muy elevado, igual que en décadas anteriores.

Las únicas escuelas que aparecen en los noticiarios de la posguerra son las de enseñanza primaria, es decir, la obligatoria. En ellas se presentan tanto a niños como a niñas. Esta situación cambia cuando se pasa a la escuela media. Al no ser obligatoria, no todas las niñas inscritas en la escuela primaria seguían sus estudios.

Existía también una disminución del número total de alumnos que continuaban los estudios de escuela media, ya que ésta era de pago. En el curso 1948-49, se registran cinco millones cuatrocientos cuarenta y nueve mil alumnos en los distintos cursos de la escuela obligatoria, de los que un $46,5 \%$ son alumnas -dos millones quinientos treinta y seis mil niñas. En la escuela media solamente hay quinientos setenta y un mil inscri- 
tos $-39,9 \%$ son niñas (Ulivieri, 1992).

A aumentar estas cifras no ayudaban las desastrosas condiciones de numerosas escuelas italianas: las infraestructuras eran decadentes, estaban masificadas y había poco profesorado. Para ayudar a los menos afortunados como los niños huérfanos de guerra, pobres o mutilados, el gobierno, junto a empresas privadas, llevan a cabo una serie de iniciativas para sacarlos de las calles donde se dedicaban a la delincuencia y escolarizarlos.

Esta realidad tiene reflejo también en los noticiarios de la posguerra. Del total de noticias analizadas sobre educación, un 26\% trata sobre niños sobre los que pesan las consecuencias de la guerra. Era necesario garantizar su educación y su supervivencia. Además de las iniciativas gubernamentales, otras instituciones como la Cruz Roja o la misma Iglesia, así como organizaciones femeninas como la UDI (Unione Donne Italiane), ayudaban a estos chicos. En Turín se creó la Città dei ragazzi (la Ciudad de los Muchachos), donde, según informa el noticiario Incom 286 (1949), «cincuenta chicos y cincuenta chicas forman la población de la ciudad, junto al cura Don Albinolo». Allí estos jóvenes estudian y aprenden un oficio que les garantizará el futuro.

Tras veinte años de fascismo, era necesario no sólo una renovación del modo de instruir, también de la moral de los italianos. En el Congreso Nacional de los Maestros Católicos que tuvo lugar en septiembre de 1948, y cuyo desarrollo captaron las cámaras de Incom, se subraya, entre los problemas de la educación de la posguerra, el de la reconstrucción moral del país. En el noticiario Incom número 189 (1948) se escucha el discurso del presidente De Gasperi, quien señala «que los maestros y el gobierno tienen una meta común: el renacimiento moral del pueblo italiano».

Para ello es necesario enseñar los principios de la democracia, como se muestra en el noticiario Incom 373 (1949): en la escuela primaria Pistelli de Roma, un profesor enseña a las alumnas el significado de la palabra «libertad». En la pizarra se ven dos dibujos: en uno, un hombre con cara de malo dice «jabajo la libertad!»; en el otro, otro hombre dice «¡viva la libertad!». El profesor pregunta a las alumnas quién de los dos «es el verdadero enemigo de la libertad». Después de la respuesta de las niñas y de un ejercicio práctico sobre el tema, el profesor matiza el concepto de libertad: «La libertad de cada uno de nosotros termina donde empieza la libertad de los demás». Es un ejemplo instructivo para muchos espectadores adultos. Sin embargo, estas ideas de libertad y democracia que se tratan de introducir en la escuela, se quedan en la mera teoría. En la educación, las mujeres no encontrarán grandes cambios, ni tampoco la libertad de la que habla el profesor de la escuela Pistelli.

En 1949 la Democracia Cristiana organizó el Congresso Nazionale della Scuola (Congreso Nacional de la Escuela), en el que se volvía a insistir en la importancia de la escuela para educar en la democracia. Así lo señala en su discurso De Gasperi, y así lo recogen las cámaras de Incom en su edición número 349 (1949). El Ministro de Educación Gonella «subraya los principios de la reforma escolar: la libertad de enseñanza, la facultad de los padres a confiar a sus hijos a las instituciones que ellos 
elijan» ${ }^{5}$. Estas pretensiones eran difíciles de llevar a la práctica. Y es que, la educación mantuvo una línea muy conservadora ${ }^{6}$, que afectaba sobre todo a las mujeres y a su futuro en la sociedad.

\section{Una escuela para el matrimonio.}

Aunque la educación fuera considerada obligatoria para todos, sin distinción de sexo, seguían existiendo dudas sobre la adecuación de los estudios a la mujer: «¿el saber, no hará daño a las mujeres? ¿A cuántos y a cuáles estudios se puede dedicar una chica?». La respuesta de la mayoría era que las mujeres tenían derecho a estudiar, pero siempre dentro de su campo, es decir, el relacionado con el hogar y la familia (Boneschi, 1998: 290).

Para la sociedad conservadora de la posguerra, la mujer sólo necesitaba saber las cosas fundamentales que le podían servir para ser una buena ama de casa: leer, escribir, sumar y restar. Algunas materias no se adaptaban a las capacidades intelectuales de las mujeres, y otras, como la economía doméstica, eran fundamentales para las niñas, pero no para los niños.

Las mujeres pueden ser instruidas, pero de forma distinta, con escuelas creadas para ellas, con disciplinas domesticadas y reducidas ad hoc, admitiéndolas en el universo del saber con extrema prudencia y de forma gradual, y sobre todo, salvaguardando aquello que para los hombres es un bien inconmensurable (en cuanto les asegura su diversidad y superioridad) la «naturaleza femenina (Ulivieri, 1992: 178).

Por ello, se consideraba que lo mejor para la educación de ambos sexos eran las escuelas separadas, o en su defecto, las clases separadas: la coeducación es la peor de las opciones desde el punto de vista moral, sobre todo porque era una ocasión para el conocimiento entre ambos sexos, y por lo tanto, podía producir un exceso de confianza (Ulivieri, 1992: 178). Hasta los años sesenta, las clases de educación primaria se dividían por sexos.

Esta separación de los escolares por géneros se hace patente en trece de las veintiuna noticias en las que aparecen niños menores de diez años, tanto en la escuela como en las colonias de verano u otros centros, es decir, en un $62 \%$ de estas noticias. De las restantes ocho noticias, en dos de ellas sólo aparecen niñas: las noticias se centran en escuelas en las que sólo hay chicas ${ }^{7}$.

5 Ídem.

6 En estos años no se llevarán a cabo reformas legislativas de la educación, ni de los programas escolares. La escuela elemental seguía el modelo estructural de la reforma fascista de Giovanni Gentile de 1923, pero los programas, hasta 1955, los dictaba la Comisión Aliada de Washburne. La escuela secundaria inferior y la superior seguían siendo las mismas de la Reforma Gentile.

7 Settimana Incom 00257 (02-03-1949), «Florencia. La casa de las mutiladitas» y Settimana Incom 00373 (07-12-1949), «Para nuestros niños: escuela de vida». 
Visualmente también es perceptible esta separación. Primero, a través de la vestimenta de los escolares: las niñas de blanco con lazo negro y los niños de negro con lazo blanco. En los planos generales que presentan a alumnos en las escuelas, se marca esta división por colores, todas las niñas a un lado y todos los niños al otro ${ }^{8}$. Al entrar a clase, en los comedores, en los pupitres, siempre aparecen separados. Segundo, a través de los planos y el montaje del noticiario se contribuye a esta separación: niños y niñas apenas comparten plano. Sólo aparecen juntos cuando se muestra un plano muy general. Los planos medios o primeros planos alternan las imágenes de niños y niñas. El noticiario Incom número 460 (1950), por ejemplo, muestra imágenes de la entrada de los estudiantes a la escuela Manzoni de Roma. En la entrada principal se distinguen dos puertas: una para alumnos y otra para alumnas. El plano general muestra las dos filas que se forman en el entrada de la escuela. Más adelante, en un plano general en picado se ve el patio del colegio, con los estudiantes en semicírculo: a la derecha domina el blanco de los uniformes de las chicas, a la izquierda el negro de los chicos. También los representantes del coro escolar están divididos por sexos.

Y en tercer lugar, se marca la diferencia entre ambos sexos por el tipo de actividades que llevan a cabo. Las niñas preparan la comida, mientras los niños aprenden algún oficio. Como en el fascismo, la clase de economía doméstica, destinada sólo a las alumnas, seguían impartiéndose en las escuelas. Se aprendía a coser, bordar, limpiar la casa, hacer la comida, y sobre todo, los mejores trucos para ser una ama de casa ahorrativa y tener contento al marido. Además de la economía doméstica, había una serie de materias que se adaptaban a los roles femeninos construidos social y culturalmente, como la puericultura, el dibujo ornamental o la gimnasia rítmica. Mientras, los niños se dedicaban a hacer el periódico del colegio, como muestra el noticiario Incom número 903 (1953): «por iniciativa de los profesores, nace el periódico Primi voli -(Primeros vuelos)-, escrito y producido materialmente por los niños» -señala el narrador de Incom.

En el centro de la Città dei ragazzi de Turín que presenta la Settimana Incom número 286, los chicos aprenden a arreglar las suelas de los zapatos, mientras las chicas cosen. El narrador lo comenta con estas palabras: «mientras tanto, las chicas se disciplinan en el orden». Después de la hora de costura, las chicas preparan la comida. «Han trabajado las pequeñas cocineras» - comenta el narrador mientras la imagen muestra las ollas llenas de comida. Mientras sirven la sopa en los cuentos, los chicos se sientan, todos juntos, en las mesas.

También las clases de gimnasia en el escuela se realizaban en momentos distintos. Por lo general, los chicos tenían un hombre como profesor, y las chicas, una mujer. Dos noticias de la Settimana Incom presentan las lecciones de gimnasia ${ }^{9}$. En una de ellas, los alumnos están en una piscina. Primero son los chicos quienes ha-

8 Ejemplos: Settimana Incom 00521 (29-11-1950), "Encuentro entre los niños de la escuela "Toti"de Roma y de los niños de la escuela elemental de Pratolongo de Vinedio, en la región de Piamonte»; Settimana Incom 00460 (28-06-1950), «En fin de curso. Ensayo coral en la Manzoni».

9 Settimana Incom 00700 (05-01-1952), «Deporte en la escuela»; Settimana Incom 00715 (31-01-1952), «Turín. 17 horas. Lección de gimnasia en la escuela». 
cen gimnasia al borde de la piscina y quienes nadan. A continuación, en filas bien organizadas, entran las alumnas. Visten traje de baño de una pieza. El narrador justifica ante los espectadores el uso del bañador, que deja ver las piernas desnudas de las nadadoras: "como el baby en la lección de italiano o de matemáticas, el bañador forma parte de la estudiante diligente». Sobre el bañador de los chicos no se hace ningún comentario, ni tampoco sobre el gorro de baño. Sin embargo, las alumnas se ponen el gorro con un toque especial: «el gorro de baño se engancha con coquetería» -dice el narrador (Settimana Incom 00700, 1952).

El noticiario Incom número 715 (1952) recoge una lección de gimnasia femenina en una escuela de Turín. «Hace cincuenta años -comienza el narrador-, la gimnasia era afable ejercicio de habitación. Se estudiaba en manuales con fotografías. Hoy también en las escuelas la lección de gimnasia se ha convertido en una clase de atletismo». Junto a este comentario, se suceden imágenes de las instalaciones deportivas de una escuela de Turín. En un gimnasio con espalderas, chicas con pantalones cortos realizan ejercicios. La faldita blanca de las alumnas de la Escuela de Educación Física de Orvieto, creada por el fascismo, se ha eliminado. Las chicas hacen gimnasia con coulottes y una camiseta. Lo que no ha cambiado es el tipo de ejercicios que se adaptan a la mujer: la gimnasia rítmica es el deporte femenino por excelencia. «Asistimos -dice el narrador de Incom- a un verdadero espectáculo de gimnasia artística en el gimnasio del instituto medio de Turín. La gimnasia rítmica -continúa- nació en Suecia para articular el cuerpo y entender los valores del tiempo musical. Hoy, las jóvenes generaciones, gracias al entrenamiento deportivo, son más bellas que hace cien años». Coincide con la idea fascista de la mejora de la raza a través del deporte, pero el tono de la noticia es totalmente distinto, así como la forma. Para el fascismo, las actividades físicas eran sinónimo de virilidad y la concepción del cuerpo femenino se entendía simplemente como una máquina moderna de reproducción social: la única función que se le puede atribuir es la de mejorar el físico de las generaciones futuras, y en especial, de los soldados. Así pues, aunque el deporte femenino se considerase antinatural, se concibió un tipo de deporte que ayudara a la mejora de la raza: la gimnasia podía mejorar las deficiencias en el desarrollo de la mujer -sin dañar su gracia y decoro-, y prepararla para su misión histórica de madre. Estas ideas permanecen en los noticiarios de la posguerra, pero no hay exaltación ni retoricismos en la presentación de las atletas, ni tampoco grandes coreografías orquestadas. Es simplemente una clase de gimnasia femenina, de la que se señalan las virtudes del deporte, especialmente las relacionadas con la función social de la mujer como madre.

Con este tipo de actividades y de materias, se formaba la identidad femenina de las niñas: «en la primera infancia la identidad femenina se delinea a través de algunos instrumentos educativos que se confirmarán a lo largo de la experiencia escolar, de manera que para toda la vida, una mujer ocupe su lugar en la sociedad y esté contenta» (Boneschi, 1998: 29).

Además de la economía doméstica como materia obligatoria para las niñas, existen en los años cincuenta una serie de institutos de formación femenina que preparan a la buena esposa y madre. En Voghera, por ejemplo, Norma Bracco, creó 
una escuela donde se enseñaba a coser, bordar, gastronomía y buenas maneras. No se aprendía nada más, porque «podría resultar desagradable para el futuro esposo» (Boneschi, 1998: 291). En las familias acomodadas, los chicos iban al instituto, y luego ir a la universidad; las chicas obtenían el diploma en economía doméstica y esperaban con confianza el día de la boda. Este tipo de institutos femeninos que formaban a las chicas para ser buenas esposas aparecen en el noticiario Incom: en la Settimana Incom 615 (1951) se explican todas las materias y actividades que las alumnas de la «Escuela de las esposas» realizan y aprenden.

En esta edición de Incom se hace una pequeña representación de una escena familiar para presentar lo que se puede aprender en esta escuela para ser una buena ama de casa. El primer plano de la escena es el retrato de una suegra preocupada. La nuera pone la mesa. A continuación, el marido llega a casa enfadado porque han llegado las facturas: su mujer gasta demasiado. La voz del narrador acompaña estas imágenes diciendo: «mediodía. El marido pretende encontrar la mesa puesta porque paga muchas facturas». Discuten. «Ella se lamenta porque es su sirvienta» - dice el narrador. Ella rompe un jarrón y él tira del mantel y rompe toda la vajilla. Los dos salen de la habitación dando un portazo a la puerta. Después de tan poco idílica imagen de un matrimonio, se presenta la escuela para aprender a ser buena esposa, cuyo emblema es un perro domado por un tigre. El noticiario ilustra las distintas actividades que las jóvenes llevan a cabo: bordar, coser, tejer, cocinar, porque, "ya se sabe, a los maridos se les caza con el paladar», poner la mesa, «un repertorio completo de todo lo que una joven en edad casadera debe saber -señala el narrador-. Aquí se forma a la esposa todo terreno» (Settimana Incom 615, 1951).

Después de presentar todas las actividades que una buena esposa debería saber, el noticiario Incom vuelve a la representación anterior: «Veamos ahora -dice el narrador- qué habría pasado si nuestra protagonista hubiera frecuentado la escuela de las esposas». Ahora todo es perfecto: cuando el marido regresa a casa, ella le llena de besos. «Ha llegado una pequeña factura -dice el narrador poniendo voz al marido-, pero cómo hace mi angelito a gastar tan poco». Se abrazan. La noticia termina con la foto de la madre de ella contenta que le guiña el ojo y con el último comentario del narrador: «Qué yerno ha encontrado mamá, bueno, bueno, bueno, tres veces bueno!».

La educación de las niñas debía ir dirigida al cuidado de la familia. En 1950 el semanal Famiglia Cristiana señalaba una serie de preceptos básicos para la formación de las niñas:

Enseñarlas a darse a los demás, a donar sus pequeñas cosas a los pobres, a los enfermos y a los que sufren. Para la niña, el centro de su vida no debe ser ella misma, sus pensamientos, sus sentimientos, su vanidad, su egoísmo, sus rizos, sus vestidos, sino que debe aprender a darse a los demás, para el bien y la felicidad de los otros (Famiglia Cristiana, 1950).

A través de estas directrices, la Iglesia pretendía que la mujer dependiera de los hombres: el padre, el marido, el hijo. 
Esta identidad femenina también se formó siguiendo los modelos familiares. Las niñas hacían lo que veían hacer a las madres, a las tías o a las abuelas. No podían salirse del modelo. Ya en los juegos de la primera infancia se observaba esta división de roles y de identidad. En una edición del noticiario Mondo Libero (1952) el Presidente de la República Einaudi junto a su esposa, entregan regalos a trescientos niños de los barrios Tiburtino y Pietralata de Roma, con motivo de las fiestas navideñas. Para los niños, cochecitos o balones, para las niñas, muñecas o cosas para la cocina.

Cuando a estas niñas se les preguntaba «¿qué quieres ser de mayor?«, la respuesta correcta era una sola: «quiero ser mamá». «Michela, nacida en 1948 , recuerda la vergüenza pasada a los ocho años en el salón de casa lleno de adultos, cuando un anciano le preguntó: '¿Qué quiere ser de mayor esta niña?' Michela contestó: 'bombero'. Todo el salón retumbó de las risas de los adultos» (Boneschi, 1998: 145).

Las convenciones sociales y la discriminación de la niñas impedía a éstas salirse de los esquemas establecidos en la familia. La educación tradicional, basada en la represión, imponía muchos más límites y prohibiciones a las niñas respecto a los niños. Entre estas prohibiciones estaban los pantalones. La ropa, como señala Marta Boneschi $(1998,34)$ constituye uno de los pilares de la formación diferenciada. Hasta los años sesenta, al igual que las mujeres adultas, las niñas sólo estaban autorizadas a llevar falda. «Las madres las adornan con lazos, cuellos, bordados, volantes, es decir, con el mayor número de adornos, como una flor que debe atraer a la mariposa».

En la escuela, el uniforme distinguía, como se ha señalado, a los niños de las niñas. Ellas llevaban baby negro con cuello blanco hasta la escuela superior, mientras que los niños se liberaban del baby después de los cinco años de escuela primaria ${ }^{10}$ : era peligroso ver la forma verdadera de una mujer, aunque fuera todavía una niña. En los noticiarios de la posguerra sobre educación se refleja perfectamente esta realidad.

Además de la escuela, en las horas extraescolares, los alumnos iban a la parroquia a jugar o a llevar a cabo actividades con los scouts. Las horas de recreo en la parroquia eran también distintas para niños y niñas, al igual que los juegos. En 1949, la revista semanal Grazia (1949) aconsejaba a las familias que inscribieran a sus hijas en los scouts porque "prepara a las mujeres a la vida, fuertes físicamente, sanas mentalmente. Buenas esposas, buenas madres. Si una chica debe cuidar su cuerpo, no debe olvidar su objetivo principal, exquisitamente femenino, el servir la causa del marido y de los hijos que tendrá».

Estos objetivos y el tipo de formación propuestos por la revista femenina Grazia difieren poco de la filosofía fascista del cuerpo. Las actividades que las niñas realizan dentro de los scouts son parecidas a las propuestas por las colonias fascistas: las chicas llevan a cabo tareas femeninas, de asistencia, mientras los chicos son los jefes de equipo.

Contra estos modelos tradicionales y discriminatorios actuaban las mujeres de la Lega nazionale delle donne italiane ${ }^{11}$. Su intención era promover la cultura y la

10 El baby femenino se eliminó de la escuela media y superior en 1968.

11 No hay ninguna noticia en los distintos noticiarios de la posguerra en la que se hable de esta 
educación entre la población femenina, tratar a las jóvenes de un modo distinto, creando intereses distintos a los de la casa y la familia. Llevaban a cabo encuentros con grupos de estudiantes de la escuela media, les prestaban buenos libros para que dejaran a un lado las novelas de amor o las fotonovelas; les concedían becas de estudio y les organizaban viajes de intercambio en el extranjero (Garofalo, 1956: 114-115). Todo ello para mejorar y ampliar la cultura y las expectativas de futuro de las nuevas generaciones de mujeres.

\section{La universidad es cosa de hombres.}

Me lo han impedido -recuerda Amelia- Se lo he pedido a mi padre, le he hecho ir a posta al colegio para hablar con la madre superiora. Ya fue una cosa excepcional que él fuese. 'Su hija querría seguir con sus estudios' -le dijo la madre superiora. 'Ya tengo chicos que llevan consigo el honor de la familia -contestó mi padre-, una mujer más en casa siempre viene bien' -. Así que ningún permiso para continuar a estudiar (Cambi, 1992: 75).

Situaciones como la de Amelia se repetían a menudo en los años de la posguerra. El mejor y, a veces único, futuro de una joven era el matrimonio. De este modo, el número de chicas en la escuela superior y en la universidad era muy escaso. El analfabetismo y la abandono escolar han estado siempre más difundidos entre la población femenina. Además, se mantenía la convicción de que la educación más allá de la escuela primaria era inútil o superflua para la ama de casa o para la trabajadora. Esto suponía un obstáculo para el acceso de las chicas a los distintos tipos de escuela (Tomasi, 1969: 58).

Antes de la guerra y en los primeros años de la posguerra, los institutos de enseñanza superior eran feudos masculinos, al igual que la universidad: las chicas constituían un quinto del total de los alumnos. Había además que tener en cuenta la misoginia de los profesores y de los compañeros: «nosotras, las chicas, manteníamos con los chicos, pocas y formales relaciones; nos dábamos de usted, dentro y fuera de la clase. No era conveniente dirigir la palabra a los chicos en los pasillos, o caminar juntos por la calle» (Tomasi, 1969: 50-56).

Poco a poco, las mujeres fueron conquistando su lugar en estos niveles educativos. En 1943, ciento dieciocho mil chicas estaban matriculadas en los institutos y escuelas de magisterio. En la universidad, sobre un total de ciento sesenta mil inscritos, cuarenta y dos mil eran mujeres (Mafai, 1979: 9). Después de la Segunda

organización, que inicia su actividad después de Segunda Guerra Mundial, con exponentes como la periodista y escritora Anna Garofalo. Muchas de las voluntarias de esta organización habían formado parte también durante la guerra de los Gruppi di Difesa della Donna (GDD), que dieron lugar en 1944 a la UDI (Unione Donne Italiane), cuyo objetivo era defender los derechos de la mujer, con independencia de la ideología política. Mujeres como Ana Garofalo y otras voluntarias se dedicaron además a la promoción de la educación entre la población femenina a través de la Lega nazionale delle donne italiane. Para conocer los intereses de las jóvenes italianas, esta organización organiza en 1948 encuentros con las estudiantes de toda Italia, para acercarse a sus aspiraciones, gustos y metas. Se encargarán además del acceso a libros y becas de estudio en la escuela media y superior (Cambi, 1992: 132). 
Guerra Mundial, la situación cambió de forma lenta: se produjo un aumento progresivo del número de mujeres inscritas en la escuela secundaria superior ${ }^{12}$. En el año escolar 1948-49, del total de inscritos en las escuelas de enseñanza superior -setecientos cuarenta y ocho mil, un $37,5 \%$ eran mujeres- doscientos ochenta y un mil alumnas.-, lo que suponía un aumento del 138\% respecto a los datos de 1943 (Mafai, 1979: 9).

A partir de 1945 se produjo en la escuela secundaria un aumento progresivo de las alumnas, sobre todo en algunas regiones de Italia como el norte, donde se pasó de un tercio del total a más de la mitad, llegando en algunos casos a una mayoría de alumnas sobre alumnos. Según algunos estudios sobre la desigualdad educativa en Italia, resulta que «las posibilidades de las mujeres han aumentado más rápidamente que las de los hombres, sobre todo entre las nacidas entre 1936 y 1951» (Ulivieri, 1992: 188).

Además de los progresivos cambios cuantitativos, se produce también una evolución cualitativa en la relación chico/chica. Se instauran relaciones de camaradería entre alumnos y alumnas; las chicas tienen mayor libertad, estilos distintos de vida, aumentan los encuentros extraescolares entre ambos sexos. La mujer empieza a integrarse en ambientes predominantemente masculinos como los institutos y la universidad.

La escasa presencia de las mujeres en la educación superior y universitaria se refleja en los noticiarios de la posguerra. Del total de las noticias analizadas en este periodo, tan sólo seis - un $19 \%$ del total - tratan sobre la enseñanza superior ${ }^{13}$. En las cuatro noticias sobre el mundo universitario, la presencia de las mujeres es marginal: no protagonizan la noticia, tan sólo aparecen imágenes de estudiantes universitarias que participan en diversas actividades académicas. Se aprecia en estas noticias el mayor número de alumnos: en la mayor parte de los planos cortos de estas dos noticias se muestra a estudiantes, profesores o autoridades masculinas ${ }^{14}$. Las mujeres sólo aparecen en planos generales, junto a otros estudiantes. Sobre la Universidad de La Sapienza de Roma, la más famosa de la capital y una de las más importantes del país, hay cerca de ciento diez noticias. De éstas, la mujer no tiene protagonismo en ninguna. Sólo en tres noticias aparecen imágenes de mujeres: dos de ellas, pertenecen al periodo estudiado ${ }^{15}$.

12 Este aumento continuó hasta el punto que a partir de los años ochenta, el número de alumnas en la escuela superior es mayor que el de alumnos.

13 Ejemplos sobre la universidad: Settimana Incom 00216 (25-11-1948), «Vida universitaria: apertura del año académico. Roma: fiesta de goliardos por la apertura del año académico»; Settimana Incom 00271 (01-04-1949), "Tradiciones estudiantiles: las "Feriae Matricularum" en Roma; y sobre escuelas de formación profesional: Settimana Incom 00776 (16-05-1952), «Vamos a la escuela: para vosotras señoras».

14 En la Settimana Incom número 514 (10-11-1950) se incluye una noticia sobre la inauguración de la Universidad de Trieste. Se nombra a las autoridades presentes: el ministro Gonella, el rector y el arzobispo. Los demás presentes en el aula magna son hombres. No se distingue entre el profesorado ninguna mujer.

15 Settimana Incom 00216 (25-11-1948), «Vida universitaria: apertura del año académico. Roma: fiesta de goliardos por la apertura del año académico»; Settimana Incom 00271 (01-04-1949), «Tradiciones estudiantiles: las "Feriae Matricularum" en Roma. 
Aunque el número de estudiantes de enseñanza superior y universitaria aumentó durante la posguerra, como se ha explicado, el tipo de estudios que llevaban a cabo eran los tradicionalmente femeninos como magisterio, letras, escuelas artísticas o institutos de formación (Tabla II). El comportamiento sexista de muchas familias italianas negaba a las hijas una instrucción universitaria a favor de un tipo de formación profesional que se adaptaba más a la mujer (Luciani, 1992: 180).

Tabla II

Estudiantes inscritos según sexo y tipo de escuela (en miles). Año escolar 1948-49

\begin{tabular}{|c|c|c|c|}
\hline Tipo de escuela y grado & \multicolumn{3}{|c|}{ Año escolástico 1948-49 } \\
\hline & Alumnos en total & No de alumnas & $\begin{array}{c}\text { \% de alumnas } \\
\text { sobre total }\end{array}$ \\
\hline Institutos profesionales & 22 & 5 & 22,7 \\
\hline Institutos técnicos & 116 & 21 & 18,1 \\
\hline Escuelas de magisterio & 3 & 3 & 100,0 \\
\hline Institutos magistrales & 57 & 52 & 89,5 \\
\hline Institutos científicos & 44 & 9 & 20,4 \\
\hline Institutos de letras & 132 & 52 & 39,4 \\
\hline Institutos artísticos & 4 & 1 & 25,0 \\
\hline Escuela secundaria & 370 & 138 & 37,3 \\
\hline
\end{tabular}

Fuente: Ulivieri, 1992: 189.

Dos de los noticiarios Incom analizados proponen para la mujer estudios profesionales para peluquera y para modelo. El título de una de estas noticias se dirige directamente a las espectadoras diciendo «vamos a la escuela. Para vosotras, señoras, porque, elegir un buen peinado -afirma el narrador- es como elegir un buen vestido» (Settimana Incom 00776, 1952), y eso sólo las mujeres pueden hacerlo. Resulta curioso, sin embargo, que los profesores de estas alumnas de peluquería sean hombres: lo que estos enseñan, según señala el narrador, es «la ciencia moderna del peinado».

Otro oficio recomendado para las mujeres es el de modelo de alta moda. Para ello tienen que ir a «la más original de las escuelas» (Settimana Incom 00182, 1948), la escuela para modelos de Varenna. El tipo de educación que reciben en esta escuela se adapta perfectamente a la naturaleza femenina: deben aprender a caminar con elegancia y estilo, como verdaderas señoritas, a cuidar su cuerpo. «En otras escuelas - dice con tono gracioso el narrador -, los libros se tiran a la cabeza, aquí deben permanecer en equilibrio sobre la cabeza. Nace así la gracia altiva e inconsciente que nos sorprende en los desfiles de moda. Ilusión de las mujeres de poder ser bellas como sois vosotras» (Settimana Incom 00182, 1948). Para entrar en esta escuela 
no es necesario leer mucho, ni estudiar demasiado. Los libros se utilizan para colocarlos en la cabeza y caminar con ellos erguidas -como muestran las imágenes de Incom. Para entrar en esta escuela lo importante es la belleza: «soñad, chicas -dice el narrador a las estudiantes de esta escuela-, el día del diploma, un diploma para el que es necesario talento y un cabello bonito, como muestran estas imágenes donde se peinan» (Settimana Incom 00182, 1948).

No obstante, en los años cincuenta, el número de chicas que continuaba sus estudios después de la escuela media aumentó. Esta situación también se produce en el ámbito universitario: aumentó el número de mujeres inscritas, pero los tipos de carrera elegidos eran prácticamente los mismos al período de entreguerras: carreras de letras, en su mayoría, y en las ciencias, enfermería o farmacia. La mayor parte de las licenciadas en letras o en ciencias naturales se dedicaban a la docencia: parecía ser la única salida laboral para las mujeres. Hasta final de los años cincuenta resultaba difícil para una mujer italiana licenciada encontrar trabajo en otras áreas profesionales fuera del magisterio (De Giorgio, 1992: 477). Después de la carrera de esposa, que era todavía la más deseada entre las jóvenes italianas de los años cincuenta, la de magisterio se encontraba en segundo lugar. En las demás seguía habiendo una mayoría masculina.

En las cuatro noticias de Incom sobre la universidad no hay ninguna referencia a los estudios que cursan hombres y mujeres. Tratan de eventos extraordinarios, como la fiesta de la licenciatura -Festae Matricularum-, o la inauguración y posterior inicio del año académico en la Universidad de Trieste. El lugar que ocupan las mujeres en estas noticias es marginal: aparecen en los planos generales, como parte de la masa de estudiantes que festeja. Sólo en una noticia se incluyen planos más cercanos de las alumnas: en la Settimana Incom 216 (1948), sobre la reapertura del año académico en la Universidad La Sapienza de Roma, hay imágenes de dos jóvenes universitarias que dan la bienvenida sobre el escenario a los políticos democristianos Gronchi y Gonella. Estas dos chicas están rodeadas de universitarios, lo que pone de manifiesto el mayor número de hombres que de mujeres en la universidad, pero es una de ellas quien da dos besos en las mejillas al ministro Gonella El narrador de Incom bromea porque la joven ha dejado la marca del pintalabios en las mejillas del ministro. Éste es el máximo protagonismo que las estudiantes universitarias alcanzan en la pantalla de cine.

En otras informaciones cinematográficas relacionadas con la educación aparecen maestras o mujeres que dirigen instituciones educativas. En el noticiario Incom 189 (1948), sobre el Congreso Nacional de Maestros Católicos, se distingue en la platea un gran número de mujeres, maestras de la enseñanza primaria. Entre las autoridades, la única mujer es la presidenta de las escuelas populares, que dirige unas palabras al auditorio. Se pone de manifiesto el elevado número de mujeres que componía el cuerpo docente italiano, sobre todo en la escuela primaria y media. También en las noticias sobre guarderías o escuelas infantiles aparecen maestras o monjas que se encargan del cuidado y la educación de los más pequeños.

A la hora de elegir una carrera o el tipo de estudios, los prejuicios de la familia y de la sociedad no ayudaban: 
si te gusta la decoración de interiores -aconseja una revista semanal femenina en los años cincuenta- no te inscribas a la facultad de arquitectura. Conténtate con el título de bachiller en el instituto artístico. Es inútil hacer frente a tanto esfuerzo, que además es malo para la salud. El licenciado en arquitectura termina trabajando en la construcción, y tú, querida, ¿no querrás mezclarte con los albañiles? (Boneschi, 1998: 292-293).

A pesar de que el ambiente no parecía propicio, el número de inscritas en la universidad aumentaba de manera progresiva ${ }^{16}$ : en 1947 se registraron 6.135 nuevas licenciadas respecto al año anterior. En los años cincuenta las posibilidades de estudio para las mujeres se habían ampliado. «El haber usufructuado de procesos de escolarización largos, ha comportado para las mujeres adultas un proceso de socialización secundaria que no se orienta sólo y exclusivamente a la familia, sino también a la exploración de las propias capacidades intelectuales» (Bimbi \& Del Re, 1997: 81).

Para las generaciones de mujeres nacidas antes de la guerra, estudiar equivalía a una transgresión, mientras dejar los estudios para casarse era una norma: interrumpir los estudios por un buen marido era considerado por padres y parientes como una sabia elección. Para la sociedad de entonces, sólo las feas estudiaban. Las jóvenes nacidas después de la guerra no estaban de acuerdo. Empezaban a cambiar los modelos femeninos y las perspectivas de futuro:

Es cierto que no deseo en ningún modo parecerme a mi madre y mucho menos a mi abuela o a mis tías. Oír continuamente cómo se proponen como modelos me irrita y a la vez me hace gracia. No es falta de estima, pero me pregunto cómo podría, incluso queriendo, parecerme a ellas cuando mi formación se ha producido en una época muy distinta y cuando son tan distintas las obligaciones y las características que el tiempo exige (Garofalo, 1956: 143).

Las nuevas generaciones de mujeres no aceptaban la inferioridad impuesta por la sociedad: «en mi clase hay chicas que son mejores estudiantes que los chicos, escriben mejor, resuelven más rápidamente los problemas de matemáticas, tienen más capacidad de síntesis. ¿Por qué un mañana deben considerarse inferiores a uno de estos compañeros?» (Garofalo, 1956: 144).

Se observa a lo largo de los años cincuenta un cambio en los modelos de las jóvenes estudiantes, además de una ampliación de las perspectivas de futuro. En una sociedad de tradición y cultura católica como la italiana, se intentaba poner un freno a la formación tanto profesional como intelectual de las mujeres, que supusiera la difusión del trabajo extradoméstico, así como de comportamientos distintos a los considerados moralmente correctos. Entre las jóvenes de los años cincuenta aumentó el rechazo a la imagen negativa que Iglesia y sociedad conservadora di-

16 Entre 1910 y 1950 se produce un aumento constante del porcentaje de mujeres sobre el total de estudiantes universitarios, que pasa del 5,8\% del 1913-14 al 26,3\% del 1950 (De Giorgio, 1992: 461). 
fundían del ambiente externo, del trabajo y de la escuela (Giuntella, 1988: 255). El temor a la corrupción de las jóvenes generaciones femeninas por parte de la sociedad moderna, típico del pontificado del Papa Pío XII, se erosionaba lentamente: se empezaban a producir profundos cambios en las costumbres y en los modelos femeninos. En ocasiones, fueron las mismas maestras los motores de estos cambios: como educadoras de las futuras generaciones, transmitieron nuevos mensajes a las alumnas. De esta manera, las maestras pasaron del tradicional papel de repetidoras acríticas de modelos neutros de cultura, a uno más innovador, el de transmisoras de nuevos modelos culturales femeninos (Ulivieri, 1992: 6).

\section{Conclusiones}

De un total de mil ciento setenta y cinco noticiarios producidos entre $1945 \mathrm{y}$ 1953, tan sólo treinta y uno -un 2,6\%- muestran aspectos relacionados con la educación femenina. Y dentro de este reducido porcentaje, son menos aún las noticias que presentan a la mujer dentro del mundo universitario: la mujer en la universidad es una gran desconocida en la información cinematográfica, que prefieren centrar su atención en la educación infantil.

De las diez noticias que hay en el Archivio Luce en las que aparecen institutos de enseñanza superior, ninguna corresponde al periodo analizado. En las noticias sobre el mundo universitario visionadas -cuatro en total-, el protagonismo no recae sobre las estudiantes. Como se ha señalado, el tema fundamental de las noticias sobre la vida universitaria italiana de este período es la celebración del inicio del año académico, por lo que las mujeres que aparecen son mera figuración.

1949 es el año en el que se producen más noticias relacionadas con la instrucción femenina en Italia. Ocho de las treinta y una noticias analizadas -un 26,5\%- datan de este año. Es probable que tenga una correspondencia con el desarrollo de la política italiana de la posguerra: en 1948 hubo elecciones generales y terminaron las labores de la Asamblea Constituyente. La información cinematográfica sobre educación refleja el empeño del gobierno por mostrar las mejoras que se estaban llevando a cabo. Aun así, se da prioridad a las noticias sobre política interior o exterior, o reconstrucción material y económica del país.

Los cambios que conllevó la guerra y la intención de reformar la escuela para hacerla más democrática no supusieron nuevos modelos educativos, en lo que a las mujeres se refiere. Aumentó la escolarización de la población femenina, pero continuaban el abandono escolar y la escasa presencia de alumnas en la escuela superior. La discriminación y los modelos educativos muy conservadores se mantuvieron durante las dos primeras décadas de la posguerra.

En los primeros ocho años de la democracia, aunque se trató de renovar la escuela y acabar con las reminiscencias fascistas, en la realidad, el modelo educativo que se impuso era muy parecido al del régimen fascista, sobre todo en aspectos relacionados con la mujer. Se depuró la ideología fascista, pero los modelos tradicionales, basados en la religión católica, se mantuvieron.

Los principios democráticos en los que querían que se basara la educación no 
eran válidos para todos. Las mujeres, ya desde niñas, debían adaptarse a los límites que la sociedad y la misma educación les imponían. El modelo educativo basado en la discriminación y en el estereotipo femenino tradicional se mantuvo todavía hasta finales de los años sesenta.

\section{BIBLIOGRAFÍA}

Arangio-Ruiz, Grazia (1986): Le donne italiane in cifre. Roma: Istituto Poligrafico dello Stato.

Bimbi, Franca \& Del Re, Alisa (1997): Genere e democracia. La cittadinanza delle donne a cinquant'anni dal voto. Turín: Rosenberg \& Séller.

BoneschI, Marta (1998): Santa Pazienza. La storia delle donne italiane dal dopoguerra a oggi. Milán: Mondadori.

CAMBI, Franco (1992): «La scoperta del "genere”. Società italiana, cultura pedagógica e questione femminile». En Simonetta ULIVIERI: Educazione e ruolo femminile. La condizione delle donne in Italia dal dopoguerra a oggi. Florencia: La nuova Italia.

De Giorgio, Michela (1992): Le italiane dall'Unità a oggi. Modelli culturali e comportamenti social. Roma: Laterza.

GARofalo, Anna (1956): L'italiana in Italia. Bari: Laterza.

GiUntella, Vittorio E. (1988): Le dolci catene: testi della controrivoluzione cattolica in Italia. Roma: Istituto per la storia del Risorgimento italiano.

InNoCenti, Marco (1995): L'Italia del dopoguerra 1946-1960. Come eravamo negli anni dal boggie-woogi alla dolce vita. Milán: Mursia.

MafaI, Miriam (1979): L'apprendistato della política. Le donne italiane nel dopoguerra. Roma: Editori Riuniti.

Perugi, Giampaolo (1978): Educazione e politica in Italia. Turín: Loescher.

TomAsi, Tina (1969): Idealismo e fascismo nella scuola italiana. Florencia: La nuova Italia.

ULIVIERI, Simonetta (1992): «Alfabetizzazione, processi di scolarizzazione femminile e percorsi professionali, tra tradizione e mutamento». En Simonetta ULIVIERI: Educazione e ruolo femminile. La condizione delle donne in Italia dal dopoguerra a oggi. Florencia: La nuova Italia.

Recibido el 02 de octubre de 2015

Aceptado el 21 de noviembre de 2017

BIBLID [1132-8231 (2017): 115-131] 